\title{
RHABDOMYOLYSIS ACCOMPANYING THE STAPHYLOCOCCAL SEPSIS
}

\section{Leonid I. DVORETSKY ${ }^{1}$, Maria A. KARNAUSHKINA ${ }^{1}{ }^{\circledR}$, Georgy 0. ZAYRATIANTS ${ }^{2}$, Elend V. SERGEEVA ${ }^{1}$, Svetlana S. BOBKOVA ${ }^{2}$}

${ }^{1}$ Department of Hospital Therapy No. 2, „I.M. Sechenov“ First Moscow State Medical University, Moscow, Russian Federation

${ }^{2}$ Municipal Hospital „S.S. Yudin“ of the Moscow Healthcare Department, Moscow, Russian Federation Received 31 May 2020, Accepted 27 July 2020

https://doi.org/10.31688/ABMU.2020.55.3.20

\begin{abstract}
Introduction. Rhabdomyolysis (RM) is a clinical and laboratory syndrome resulting from skeletal muscle damage, with the release of a big number of intracellular substances of myocytes into the systemic circulation and endotoxemia. The entry of the muscle destruction products into the systemic circulation leads to the development of systemic manifestations, serious disorders in homeostasis, multiple organ failure syndrome, including acute renal failure, often threatening the patient's life.
\end{abstract}

Case report. A rare case of RM in a patient with staphylococcal sepsis (SS) and development of multiple organ failure is described. The diagnosis of RM was confirmed by the results of pathological and anatomical studies. Possible causes of RM in staphylococcal sepsis are discussed here.

Conclusions. Only a few cases of RM upon SS were found in the literature. The development of RM in combination with the systemic inflammatory reaction syndrome in SS exacerbates the course of the disease and worsens its prognosis. Therefore, the timely diagnosis of RM and appropriate treatment are extremely important. The mechanism of RM development upon

\section{RÉSUMÉ}

Rhabdomyolyse accompagnant la septicémie staphylococcique

Introduction. La rhabdomyolyse est un syndrome clinique et de laboratoire résultant de lésions musculaires squelettiques avec libération d'un grand nombre de substances intracellulaires de myocytes dans la circulation systémique et endo-toxémie. L'entrée des produits de destruction musculaire dans la circulation systémique entraîne le développement de manifestations systémiques, de troubles graves de l'homéostasie, du syndrome de défaillance multiviscérale, y compris une insuffisance rénale aiguë, menaçant souvent la vie du patient.

Rapport de cas. Un cas rare de rhabdomyolyse chez un patient souffrant de septicémie staphylococcique et de développement d'une défaillance d'organes multiples est décrit. La présence de la rhabdomyolyse est confirmée par les résultats d'études pathologiques et anatomiques. Les causes possibles de la rhabdomyolyse dans la septicémie staphylococcique sont discutées ici. Conclusions. Seuls quelques cas de rhabdomyolyse à fond de septicémie staphylococcique ont été trouvés 
SS is complex. After staphylococcus was isolated from the affected muscles in a patient with SS, one of the first descriptions of RM upon SS suggested the role of direct invasion of the infectious agent into the muscles, followed by the development of „pyomyositis." Another mechanism for RM occurrence of PM may be the presence of toxin upon the staphylococcal toxic shock syndrome in patients with SS.

Keywords: rhabdomyolysis, staphylococcal sepsis, infectious endocarditis, acute renal failure.

\section{List of abbreviations:}

RM - rhabdomyolysis

SS - staphylococcal sepsis

ARN - acute renal failure

IE - infectious endocarditis

CPK - creatine phosphokinase

ALT - alanine aminotransferase

AST - aspartate aminotransferase

\section{INTRODUCTION}

Rhabdomyolysis (RM) is a clinical and laboratory syndrome resulting from skeletal muscle damage, with the release of a large number of intracellular substances of myocytes into the systemic circulation (myoglobin, lysosomal and mitochondrial enzymes, histamine, serotonin, oligo- and polypeptides, etc.) and endotoxemia. The entry of the muscle destruction products into the systemic circulation leads to the development of systemic manifestations, serious disorders in homeostasis, multiple organ failure syndrome, including acute renal failure (ARN), often threatening the patient's life.

The various causes of RM (traumatic injuries, metabolic disorders, epilepsy, excessive muscle stress, drugs, etc.) specifically include various infections ${ }^{1,2}$. A search in the Medline system for the publication of RM cases with infections over 30 years (1966-1996) returned information on viral and bacterial infections as the cause of RM in 59 and 60 cases, respectively ${ }^{3}$.

RM is relatively rare against a background of staphylococcal infections, particularly, staphylococcal sepsis (SS). The first reports of RM upon SS in children and adults appeared in the 1980s. The pediatric literature described a case of RM upon SS in a 15-year-old boy ${ }^{4}$. The earliest description of RM upon SS in adults is related to a 70-year-old patient dans la littérature, et au deuxième millénaire, seules trois observations ont été publiées. Le développement de la rhabdomyolyse en combinaison avec le syndrome de réaction inflammatoire systémique dans les septicémies staphylococcique exacerbe le cours de la maladie et aggrave son pronostic, et donc le diagnostic rapide de la rhabdomyolyse et le traitement approprié sont extrêmement importants. Le mécanisme de développement de la rhabdomyolyse sur septicémie staphylococcique est complexe. Après que le staphylocoque ait été isolé à partir de muscles affectés chez un patient atteint de septicémie staphylococcique, l'une des premières descriptions de la rhabdomyolyse sur septicémie staphylococcique a suggéré le rôle d'une invasion directe de l'agent infectieux dans les muscles, suivie du développement d'une «pyomyosite». Un autre mécanisme pour l'apparition de la rhabdomyolyse peut être la présence de toxines sur le syndrome de choc toxique staphylococcique chez les patients atteints de septicémie staphylococcique.

Mots-clés: rhabdomyolyse, septicémie staphylococcique, endocardite infectieuse, insuffisance rénale aiguë.

with septic shock, ARN development and resulting in death ${ }^{5}$. The following case of RM upon SS (the presence of staphylococcus in the blood and urine) without signs of shock and ARN, with a positive treatment outcome, was described two years later in a 20-year-old patient with infectious endocarditis (IE) ${ }^{6}$, and two years later two more cases of RM upon SS were reported ${ }^{7,8}$. Recent publications of the last century cover two cases of RM upon SS: in one patient with acquired immunodeficiency syndrome $e^{9}$, and in another - with staphylococcal pneumonia ${ }^{10}$. It is noteworthy that in almost 30 years after the first descriptions of RS upon SS, there were no publications on this topic, and only in the second millennium did individual information reappear. Thus, a report was published on the development of RM in a 12-year-old child with staphylococcal IE, manifested by myalgia, fever, and secretion of dark urine ${ }^{11}$. In adults, two cases of RM upon IE caused by methicillin-sensitive staphylococcus have been described. One patient previously operated for a congenital malformation developed IE complicated by severe RM with high CPK indices (up to $49068 \mathrm{IU}$ ), successfully treated with antibiotics followed by surgical intervention ${ }^{12}$. In another patient with IE, RM was diagnosed in combination with purpura, purulent pericarditis and intracerebral hematoma. Despite intensive therapy (antibiotics, drainage of the pericardial cavity and cerebral hematoma), a fatal outcome occurred ${ }^{13}$. 
In this article, we present a patient with severe RM that developed against the background of SS.

\section{Case presentation}

A 46-year-old man was admitted to the neurological department of the State Clinical Hospital „S.S. Yudin“ (Moscow, Russian Federation) on June 28, 2019, with complaints of pain in the lower spine, and weakness in the legs. The medical history included type 2 diabetes mellitus, for which he received insulin preparations of short and prolonged action, nephrectomy for urolithiasis, polytrauma (fracture of ribs, craniocerebral trauma, fractures in the vertebra, contusion of the liver and spleen) at the age of 20 years.

The condition at admission is satisfactory. The consciousness is clear. Forced position on the back. Vesicular breathing, without wheezing, breath rate $16 / \mathrm{min}$. The heart sounds are rhythmic, heart rate $80 / \mathrm{min}$, blood pressure 120/80 $\mathrm{mm} \mathrm{Hg}$. The abdomen is soft and painless on palpation. The liver and spleen are not enlarged. No acute neurological and surgical pathology, or foci of infection were found. We noted the changes of laboratory tests in dynamics. Peripheral blood showed leukocytosis (32-35 x $\left.10^{9} / \mathrm{L}\right)$ with a sharp shift to the left $(17-37 \%$ of stab neutrophils) to the appearance of young forms in the blood (myelocytes, metamyelocytes). Hemoglobin and platelet counts were within the normal range. Biochemical blood tests revealed an increase in the level of C-reactive protein (CRP) $(302-440 \mathrm{mg} / \mathrm{L})$, procalcitonin $(5.3-17.02 \mathrm{ng} / \mathrm{mL})$, AST and ALT activity (118 IU/L and $101 \mathrm{IU} / \mathrm{L}$, respectively), creatine phosphokinase (2200-2700 IU/L), urea (16-23 $\mathrm{mmol} / \mathrm{L})$, creatinine $(153.234 \mathrm{mmol} / \mathrm{L})$, potassium (5.2-5.5 mmol/L), glucose $(20 \mathrm{mmol} / \mathrm{L})$. During his stay in the neurological department, the patient's condition deteriorated, with sharp pain in the muscles of the limbs, pain on palpation of the muscles, disorders of the central nervous system (lethargy, confusion), a decrease in the blood pressure to $90 / 70 \mathrm{~mm} \mathrm{Hg}$. Myoglobin $(14350 \mathrm{ng} / \mathrm{mL}$ ) was detected in the blood. Brown urine secretion was marked. The patient was transferred to the intensive care unit on July 01, 2019, where intubation of the trachea, and catheterization of the internal jugular vein were performed, followed by artificial ventilation, hemodiafiltration, and noradrenaline infusion.

Ultrasound of the soft tissues of the medial surface of the upper third of the thigh revealed an increase in echogenicity, without clear delineations, with single an-echogenic inclusions (edema?, infiltrate?). No fluid accumulation detected in soft tissues. Electrocardiogram showed episodes of atrial flutter, arrested by cordarone. The values of urea $(45.3 \mathrm{mmol} / \mathrm{L})$, creatinine $(332 \mu \mathrm{mol} / \mathrm{L})$, CPK $(4809$ $\mathrm{U} / \mathrm{L})$, and lactate dehydrogenase (729 U/L) were increasing. The microbiological examination of the blood and urine revealed Staphylococcus aureus sensitive to methicillin. Antibacterial therapy (oxacillin, linezolid) was prescribed. Despite intensive therapy, the condition deteriorated, progressively and the patient died on July 11, 2019.

The positive diagnosis was: Sepsis from undiagnosed origin. Systemic inflammatory reaction syndrome. Rhabdomyolysis. Multiple organ failure. Poly segmental pneumonia. Diabetes mellitus type 2 .

The pathological diagnosis after necropsy was: Sepsis. Septic shock: shocked kidneys, liquid blood in the cavities of the heart and large vessels. Bilateral focal-confluent pneumonia in 6-9 segments. Multiple organ failure syndrome: parenchymal dystrophy of the liver, myocardium, kidneys. Myocardial infarction in the posterior wall of the left ventricle, with dimensions of $2.5 \times 3.0 \mathrm{~cm}$ about one day old. Focal necrosis of the ileum. Acute erosion of the stomach and duodenum. Pulmonary edema. Cerebral edema. Attention was drawn to the change in the appearance of striated muscles, especially the femoral and iliac muscles, which were mottled, with uneven blood supply and flabby ("boiled meat" appearance) (Fig. 1 a,b).

\section{Discussion}

The presence of a systemic inflammatory reaction syndrome (marked leukocytosis with a shift to myelocytes, a high-level of CRP), the results of the microbiological study (Staphylococcus aureus in the blood and urine), and a high-level of procalcitonin indicated the development of SS, although the primary site of infection could not be defined. Peculiarities of SS progression in the form of myalgia syndrome in combination with elevated CPK, ALT, AST, the presence of myoglobin in the blood, brown urine, and ultrasound data on soft tissues indicated the diagnosis of RM, as a rare complication of SS. This clinical and laboratory syndrome raised the suspicion of polymyositis, which had to be differentiated from RM in various pathological processes. Similar difficulties in the differential diagnosis were reported in one of the RM case descriptions upon SS in a patient with IE, successfully treated with antibiotics, followed by the disappearance of RM signs ${ }^{14}$. Muscle lesion was confirmed by autopsy and subsequent histological examination.

Only a few cases of RM upon SS were found in the literature, and in the second millennium, only three observations were published ${ }^{12-14}$. The development of RM in combination with the systemic 


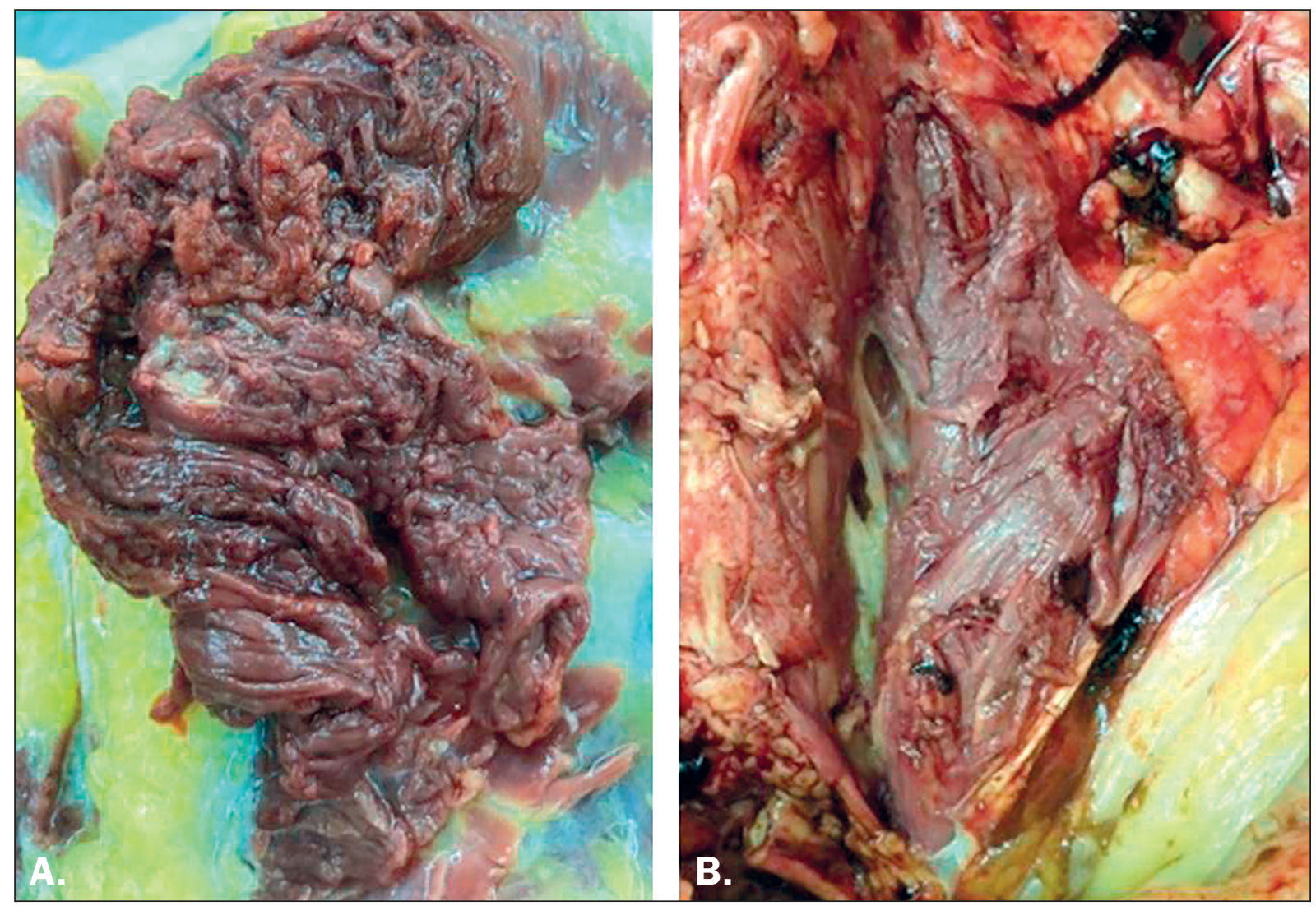

Fig. 1 a,b. Iliac muscles of the mottled flabby appearance with uneven blood supply.

inflammatory reaction syndrome in SS exacerbates the course of the disease and worsens its prognosis. Therefore, the timely diagnosis of RM and appropriate treatment are extremely important.

The mechanism of RM development upon SS is complex. After staphylococcus was isolated from the affected muscles in a patient with SS, one of the first descriptions of RM upon SS suggested the role of direct invasion of the infectious agent into the muscles, followed by the development of "pyomyositis." Another mechanism may be the presence of toxins upon the staphylococcal toxic shock syndrome in patients with $\mathrm{SS}^{15}$.

Among other toxic mechanisms not related to the toxic shock syndrome, are the staphylococcal enterotoxins associated with the development of RM in a patient with SS, who was found to have the genes encoding staphylococcal enterotoxins $\mathrm{C}, \mathrm{G}$ and I. One of the mechanisms of myocyte damage upon infections may be the release of interleukin-1 from cells, which is, moreover, a pyrogen during fever development ${ }^{16}$. The role of the increased content of intracellular calcium entering the cells under the action of prostaglandins and leading to cell destruction activated by neutral proteases is not excluded ${ }^{17}$. Various additional risk factors may contribute to the development of RM upon SS (statins, alcohol consumption, etc) ${ }^{18}$. In our patient, one additional factor may be considered the presence of diabetes mellitus.

\section{Conclusions}

One of the RM complications is renal damage, with the development of $A R F^{19}$. The incidence of ARF reaches $40 \%$ among all cases of $\mathrm{RM}^{20}$. $\mathrm{RM}$ is the cause of $15 \%$ of ARF cases ${ }^{21}$. The main pathogenetic mechanism of renal damage upon RM is the appearance of myoglobin, having a nephrotoxic effect, in the blood. Furthermore, the fluid redistribution into the muscles results in hypovolemia, leading to renal hypoperfusion. Attempts to predict the risk of developing ARF in patients with RM based on the values of $\mathrm{CPK}$, creatinine, potassium, calcium, and the content of myoglobin in urine were inconclusive ${ }^{20}$. An additional factor for the development of ARF in our patient could be the nephrectomy in the past.

The treatment of SS patients complicated by RM includes, along with adequate antibacterial therapy, the correction of hypovolemia, electrolyte imbalance (acidosis, hyperkalemia, hypercalcemia), and the hemostatic system, alkalization of urine in order to prevent the nephrotoxic effect of myoglobin, as well 
as the methods of replacement therapy for ARF (hemodialysis) $)^{22}$.

\section{Author Contributions:}

L.I.D., E.V.S., and S.S.B. were responsible for the diagnostic procedures, clinical diagnosis, and treatment decisions. G.O.Z. made the histopathological diagnosis. L.I.D. and M.A.K. analyzed the literature and wrote the manuscript. All authors have read the text and reached an agreement for the manuscript text.

\section{Compliance with Ethics Requirements:}

„The authors declare no conflict of interest regarding this article"

„The authors declare that all the procedures and experiments of this study respect the ethical standards in the Helsinki Declaration of 1975, as revised in 2008(5), as well as the national law. Informed consent was obtained from the patient included in the study"

"No funding for this study"

\section{Acknowledgements:}

None

\section{References}

1. Blanco JR, Zabalza M, Salcedo J, Echeverria L, García A, Vallejo M. Rhabdomyolysis of infectious and noninfectious causes. South Med J. 2002;95(5):542-4.

2. Lionte C, Sorodoc L, Petris O, Sorodoc V, Bologa C, Anton G. Non-traumatic rhabdomyolysis in medical practice. Rev Med Chir Soc Med Nat Iasi. 2009;113(4):1025-3.

3. Singh U, ScheId WM. Infectious etiologies of rhabdomyolysis: three case reports and review. Clinical Infectious Diseases 1996;22:642-9.

4. Adamski GB, Garin EH, Ballinger WE, Shulman ST. Generalized nonsuppurative myositis with staphylococcal septicemia. J Pediatr 1980;96:694-7.

5. Lannigan R, Austin TW, Vestrup J. Myositis and rhabdomyolysis due to Staphylococcus aureus septicemia. Infect Dis. 1984;150(5):784.

6. Saito H, Yoshii F, Ishihara T, Shinohara Y. Rhabdomyolysis associated with staphylococcal septicemia. Rinsho Shinkeigaku (Clin Neurol) 1986;26:693-7.
7. Kawamoto R, Fujii Y, Tao S. An autopsy case of rhabdomyolysis associated with staphylococcal septicemia. J Jpn Soc Intern Med 1988;77:1278.

8. Taillan B, Vinti H, Fuzibet JG, Fournier JP, Montagne N, Dujardin P. Non-traumatic rhabdomyolysis in Staphylococcus aureus septicemia. Presse Med. 1988;17(36):1860-1.

9. Wu AW, Benirschke K, McCutchan JA. Rhabdomyolysis and Staphylococcus aureus septicemia in a man with the acquired immunodeficiency syndrome. West J Med 1990; 152:716-719.

10. Bando T, Fujimura M, Noda Y, Ohta G, Hirose J, Matsuda T. Rhabdomyolysis associated with bacteremic pneumonia due to Staphylococcus aureus. Intern Med 1994;33:454-5.

11. Bandi S, Chikermane A. Rhabdomyolysis in a child secondary to Staphylococcus aureus endocarditis. J Global Infect Dis 2009;1(2):146-8.

12. Ravry C, Fedou AL, Dubos M, et al. Severe rhabdomyolysis associated with Staphylococcus aureus acute endocarditis requiring surgery. Surg Infect (Larchmt). 2015;16(6):840-2.

13. Georgescu AM, Azamfirei L, Szalman K, Szekely E. Fatal endocarditis with methicilin-sensible Staphylococcus aureus and major complications: rhabdomyolysis, pericarditis, and intracerebral hematoma. A case report and review of the literature. Medicine 2016;95 (41): e5125.

14. Ojeda J, López-López L, González A, Vilá LM. Infective endocarditis initially presenting with a dermatomyositis-like syndrome. BMJ Case Rep 2014;2014:bcr2013200865.

15. Scobie BA. Staphylococcal toxic shock: Two fulminant cases with recovery. NZ Med J 1982;95:145-7.

16. Baracos V, Rodemann P. Dinarello CA, et al. Stimulation of muscle protein degradation and prostaglandin E2 release by leukocytic pyrogen (interleukin-1): a mechanism for the increased degradation of muscle proteins during fever. $N$ Eng J Med 1983;308: 553.

17. Clowes GH, George BC, Villee CA, et al. Muscle proteolys is induced by a circulating peptide in patients with sepsis or trauma. N Engl J Med 1983;308:545.

18. Gheorghe G, Toth PP, Bungau S, et al. Cardiovascular risk and statin therapy considerations in women. Diagnostics 2020;10:483.

19. Stoicescu M, Csepento C, Mutiu G, Bungau S. The role of increased plasmatic renin level in the pathogenesis of arterial hypertension in young adults. Romanian Journal of Morphology and Embriology 2011;52(Suppl. 1):419-423.

20. Khan FY. Rhabdomyolysis: a review of the literature. Neth J Med. 2009;67(9):272-283.

21. Kasaoka S, Todani M, Kaneko T, et al. Peak value of blood myoglobin predicts acute renal failure induced by rhabdomyolysis. J Crit Care. 2010;25(4):601-604.

22. Better OS, Abassi ZA. Early fluid resuscitation in patients with rhabdomyolysis. Nat Rev Nephrol. 2017;7(7):416-422. 